\title{
COMPARATIVE STUDY OF THE NEUROPSYCHOLOGICAL AND NEUROIMAGING EVALUATIONS IN CHILDREN WITH DYSLEXIA
}

\author{
Rodrigo Genaro Arduini', Simone Aparecida Capellini², Sylvia Maria Ciasca ${ }^{3}$
}

\begin{abstract}
We analyzed re t rospectively the neuroimaging exams of children with a confirmed diagnosis of dyslexia and correlated our findings with the evaluation of higher cortical functions. We studied 34 medical files of patients of the Ambulatory of Neuro-difficulties in Learning, FCM/UNICAMP. All of them had been sent to the ambulatory with primary or secondary complaints of difficulties at school and were submitted to neuropsychological evaluation and imaging exam (SPECT). From the children evaluated $58.8 \%$ had exams presenting dysfunction with $47 \%$ presenting hypoperfusion in the temporal lobe. As for the higher cortical functions, the most affected abilities were reading, writing and memory. There was significance between the hypoperfused areas and the variables schooling, reading, writing, memory and mathematic reasoning. The SPECTs showed hypoperfusion in areas involved in the reading and writing processes. Both are equivalent in terms of involved functional areas and are similar in children with or without specific dysfunctions in neuroimaging.
\end{abstract}

KEY WORDS: dyslexia, neuroimaging, neuropsychology.

\begin{abstract}
Estudo comparativo das avaliações neuropsicológicas e de neuroimagem em crianças com dislexia
RESUMO - Analisamos re t rospectivamente exames de neuroimagem de crianças com diagnóstico de dislexia e correlacionamos os achados com avaliação das funções corticais superiores. Estudamos 34 prontuários de pacientes atendidos no Ambulatório de Neuro-Dificuldades de Aprendizado, FCM/UNICAMP, no período de 1994 a 2002. Todas foram encaminhadas com queixa primária ou secundária de dificuldade escolar e submetidas à avaliação neuropsicológica e exame de imagem (SPECT). Das crianças avaliadas, 58,8\% apresentaram exames alterados. Dentre as alterações, 16 possuíam hipoperfusão no lobo temporal. Nas funções corticais superiores, as habilidades mais prejudicadas foram leitura, escrita e memória. Houve significância entre as áreas hipoperfundidas com a variável escolaridade, leitura, escrita, memória e raciocínio matemático. Os SPECTs mostraram hipoperfusão em áreas envolvidas nos processos de leitura/escrita. Ambos se equivalem em termos de áreas funcionais e são semelhantes nas crianças com e sem alterações específicas à neuroimagem.
\end{abstract}

PALAVRAS-CHAVE: dislexia, neuroimagem, neuropsicologia.

The act of reading, apparently simple, involves a whole linguistic, anatomic and neuropsychological process'; there fore, a failure in this process of correspondence of sounds (phonemes) with graphical symbols (graphemes), or in case this correspondence does not occur, brings about the specific learning disability (SLD), known as dyslexia. Some authors ${ }^{2,3}$ suggest that dyslexia consists of a suspension or deceleration in the normal sequence of acquisitions of the different procedures for the identification of a word, whose deficits result in a ru $\mathrm{p} t \mathrm{u}$ re of the underlying neurological system. The SLD in the recognition of writ- ten words may affect children or adults; and this difficulty, which varies in intensity and nature, may persist until adulthood under the form of misspelling of w o rds or difficulty in assimilating written text, or also, difficulty in learning a foreign language ${ }^{4}$. The prevalence of dyslexia in developed countries is from 8 to $10 \%$ of school-aged children in initial grades, with significant predominance in males. There have been several attempts to explain the etiology of dyslexia in the last years, suggesting the implications of various factors, such as: Genetics - explaining the prevalence in males, connected to the existence of family

Discipline of Infant Neurology, Department of Neurology, Faculty of Medical Sciences State University of Campinas, Brazil (UNICAMP): ${ }^{1}$ Student in the $6^{\text {th }}$ year of Medical School; ${ }^{2}$ PhD. Professor Participating in the Program of Post-Graduation in Medical Sciences; ${ }^{3} \mathrm{PhD}$. Professor of the Discipline of Child Neurology.

Received 1 September 2005, received in final form 16 January 2006. Accepted 20 February 2006.

Dra. Sylvia Maria Ciasca - Departamento de Neurologia - FCMIUNICAMP / Caixa Postal 6111 - $13083-970$ Campinas SP - Brasil. E-mail: sciasca@mpc.com.br 
heritage, notably in the chromosomes 6 and $15^{5}$. Ce rebral lateralization - or GBG theory (Geschwind-Beh a n-G a la bu rda), suggesting that high levels of fetal testosterme produce reduction in the neuroanatomic and functional development of the left hemisphere of the brain. The act of reading activates several cortical areas generating the interaction mainly of areas like the superior posterior temporal gyrus (Wernicke's a rea), the angular gyrus (Brodmann's area 39), the striate cortex (Brodmann's area 17), the inferior frontal gyrus (Broca's area) and, marginally, Brodmann's areas 46,47 and 116-9.

The SPECT can demonstrate important disorders in the cerebral blood flow ${ }^{10}$ besides observing other structures and deficient regions in the learning process of patients with dyslexia. Authors found disorders in the blood flow of the left hemisphere in dyslexic adults and children during reading tasks, indicating that their brains operate in an inefficient form during this activity ${ }^{11,12}$. Therefore, in the last years, the cognitive processes were understood through neuroimaging techniques which correlated the stages of information processing with the activation/inactivation of neuronal circuits ${ }^{13,14}$.

Based on the above explained, the objective of this work was to correlate the findings of the evaluation of higher cortical functions with the results of the neuroimaging exam (SPECT) in children diagnosed with dyslexia.

\section{METHOD}

Subjects - A total of 50 medical files were analyzed of children taken to the ambulatory of learning disab ilities, Discipline of Infant Neurology, FCM/UNICAMP, São Paulo Brazil, with specific complaints of difficulty in reading and writing. The inclusion criteria were: having specific difficulty in reading and writing; chronological age ranging from 6 years and 0 months to 14 years and 11 months; schooling ranging from kinderg a rten to $8^{\text {th }}$ grade, attending a public school; having been thoroughly diagnosed in the neuropsychological and neuroimaging evaluations; not having any complaints of physical, mental, social and emotional nature associated. The exclusion criteria were: age above the established limit; other diagnosis not related to reading and writing; incomplete diagnosis in the neuropsychological and neuroimaging evaluations; associated complaints of physical, mental, social and emotional nature identified through complementary exams performed by interdisciplinary team; not being attending school.

Based on such criteria, a final number of 34 children were chosen, being 24 males $(70.6 \%)$ and 10 females (29.4\%), with 9.32 years average age, attending from kindergarten to $4^{\text {th }}$ grade of a public school, medium-low socioeconomic level, determined by the protocol of patient profile, made by Hospital das Clínicas/UNICAMP.

\section{Material}

Elaboration of protocols for the analysis of data collect ed in the folders: two protocols were elaborated

1. Protocol for analysis of the data in the folders, containing: identification of the subjects, results of the traditional neurological examinations, results of the evolutive ne u rological examination, results of the neuropsychological evaluation, results of the evoked potential: cognitive (P300), auditory and visual, results of the SPECT exams and other imaging exams.

2. Protocol for the analysis of the imaging exams, containing the identification of the subjects, hemispherical location of the dysfunction, intensity of perfusion and affected area.

Analysis of the diagnostic instruments obtained in the medical files

1. The Wechsler intelligence scale for children ${ }^{15}$, for children aged 5 to 15 , whose basic objective is to measure quantitatively the general cognitive level, through mental operations.

2. The Luria-Nebraska neuropsycholog ical battery for children ${ }^{16}$, with the objective of evaluating 10 neuro psychological areas which produce and determine behavior and which implicate in the interaction of cerebral areas through a functional system.

3. Traditional neurological examination.

4. Evolutive neurological examination ${ }^{17}$.

5. Neuroimaging exam: SPECT, with the objective of verifying the functioning of cer ebral blood flow in terms of pe rfusion, that is, observing cerebral activity through the areas with hypoperfusion (lower activity or lower flow) and hyperperfusion (higher activity or higher flow).

After all the evaluations were performed, the subjects who presented cognitive level corresponding to their chronological age, specific disabilities in reading, writing, memo ry and presence of minor signals, with absence of other disabilities or deficits, were classified as dyslexic. Such evaluations were performed by the same professionals of the team of the laboratory of rese a rh on learning disabilities and difficulties and attention deficit - DISAPRE.

Statistical analysis of the results - Initially all the variables were studied in a descriptive way, through the calculus of absolute and relative frequencies, and as for the continuous variables, through the calculus of average, standard deviation, percentage ( $25 \%$ and $75 \%)$, median, minimum and maximum values. In order to study the association of the categorical variables with the response variable, each one of them was studied bivariately through the Fisher exact test considering $\alpha=5 \%{ }^{18}$. As for the analysis, the program SAS version 8.2 was used.

\section{RESULTS}

As for sex, age and schooling - We analyzed the 39 medical files, 28 were males (71.8\%) and only 11 $(28.2 \%)$ were females. The chronological age varies from 6 years and 0 months to 14 years and 11 months 


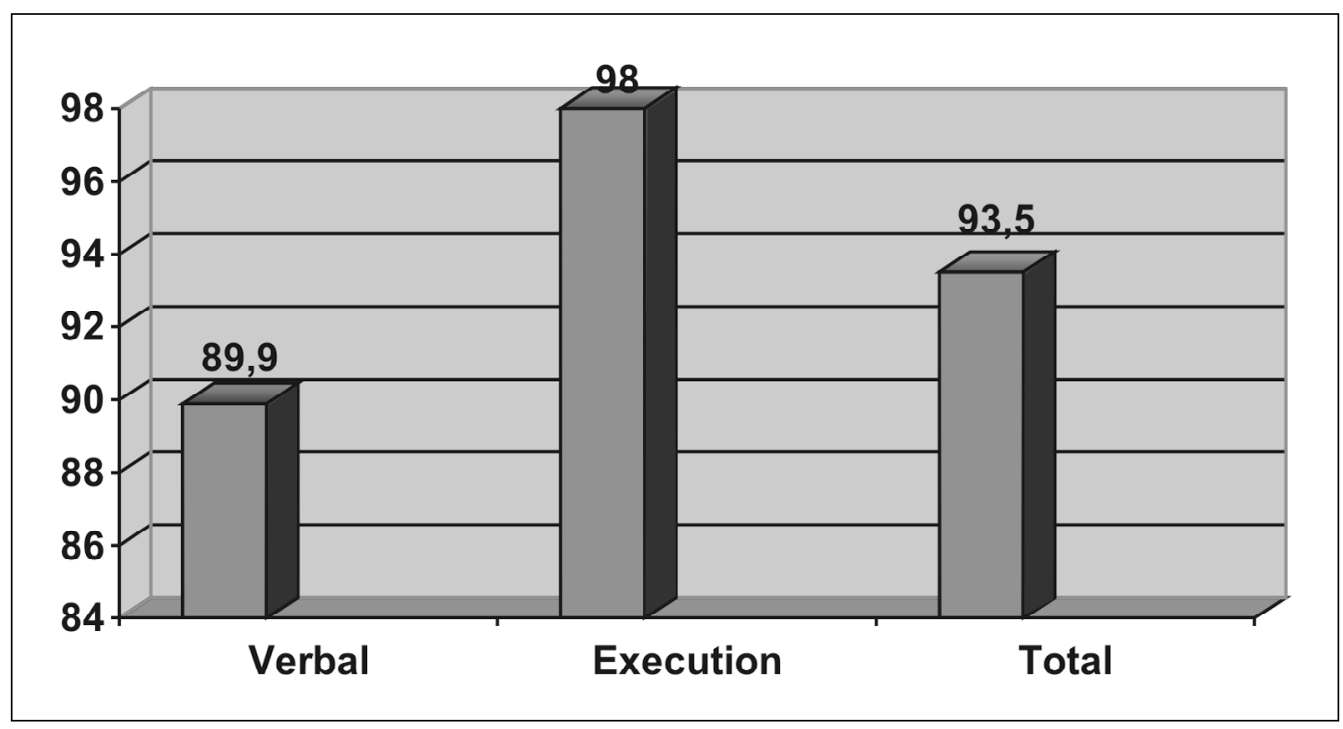

Chart 1. Distribution of the intelligence quotient (IQ): verbal, execution and total.

old, with higher incidence in the range of 8 years and 0 months to 9 years and 11 months old $(43.6 \%)$. As for schooling, the children attended from kindergarten to $4^{\text {th }}$ grade of public schools in the city of Campinas - São Paulo - Brazil and its region.

As for the neuropsychological evaluation - In the ne u ropsychological evaluation, $30(76.9 \%)$ children presented some kind of difficulty, only three (7.6\%) completely scored the tests correctly and six had no evaluation in their medical files, which were performed later for their inclusion in the group.

As for the cognitive level: The intelligence quotient (IQ) was subdivided in 3 parts: verbal IQ which ranged from 53 , considered mild mental retardation (MR), to 124 , being the average suggested classification of 89.9 (normal classification); the execution IQ ranged from 63 (moderate M.R.) to 130 (superior), with an average of 98; and the total IQ from 57 (moderate M.R.) to 130 (superior) with average of 93.5, according to Chart 1.

As for the evaluation of higher cortical function: The result of the Luria Nebraska battery (LNB) demonstrated significant difficulty in the tests involving memory $(45.5 \%)$, reading $(51.5 \%)$, writing $(57.6 \%)$ and mathematic calculus $(45.5 \%)$.

As for the neuroimaging exam - In the SPECT, from the 39 revised exams, $19(48.7 \%)$ were normal and $20(51.3 \%)$ altered. The alterations were distributed according to the affected area, only one lobe $(95 \%)$, more than one lobe $(5 \%)$, hemisphere (um hemisphereaffected $55 \%$; both hemispheres plus cere-
Table 1. Results of the affected areas in the SPECT.

\begin{tabular}{lcc}
\hline Localization & N 39 & $(\%)$ \\
\hline One affected lobe & 19 & 95 \\
More than one affected lobe & 1 & 5 \\
One hemisphere & 11 & 55 \\
Two hemispheres & 4 & 20 \\
Two hemisphere + cerebellum & 3 & 15 \\
Only cerebellum & 2 & 10 \\
\hline
\end{tabular}

bellum $20 \%$ ) and cerebellum (10\%), according to Table 1.

As for the affected area, $10 \%$ presented hypoperfusion in the frontal, parietal lobes and cerebellum respectively, $20 \%$ had occipital hypoperfusion and $80 \%$ in the temporal lobe.

As for the correlation between the SPECT and the ne uropsychological evaluation - Statistical analysis was made correlating the altered imaging exam and the normal one in relation to the neuropsychological evaluation, considering the prevalence ratio $(\mathrm{Cl}$ $95 \%$ ) with the Fisher test ( $p$-value), where the values were within the expected for the test, but demonstrated a tendency of correlation between the altered exam and the reading, writing, mathematics and memorytests of the neuropsychological evaluation, according to Table 2 .

The refore, the results demonstrated that despite the absence of significant differences between groups 


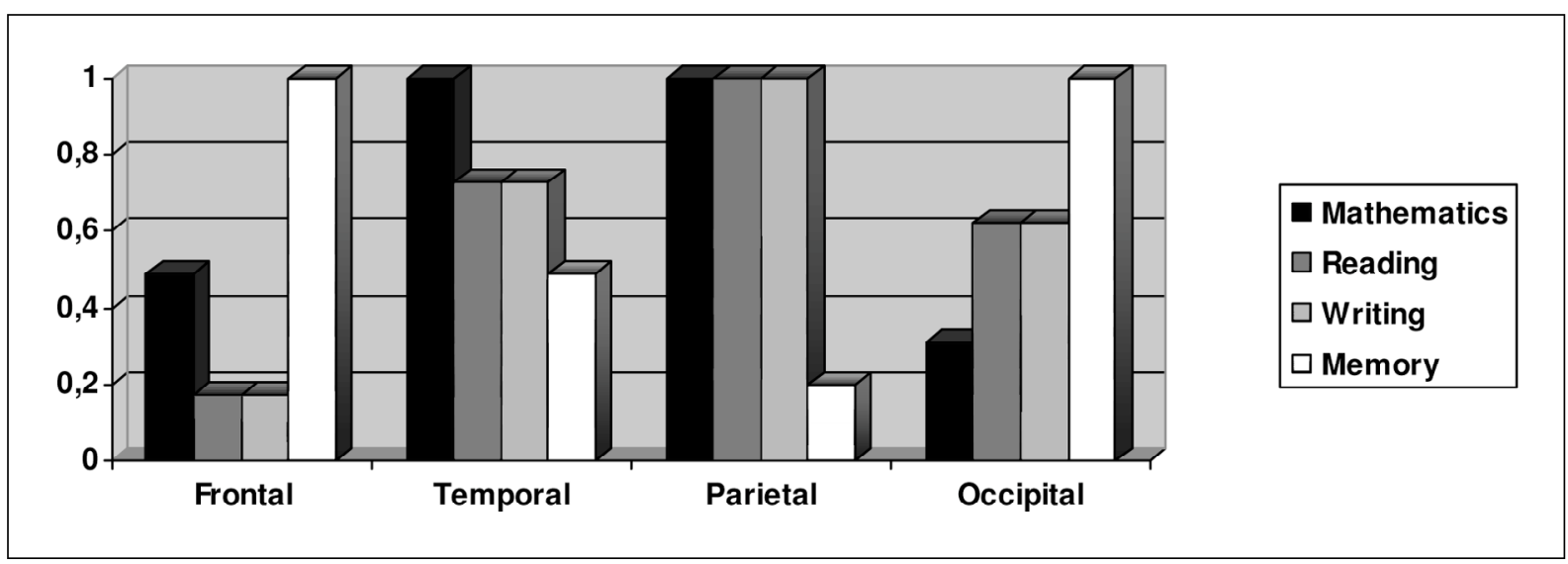

Chart 2. Distribution of the value of $p(P)$ in the reading, writing, mathematics and memory tests with the cerebral areas.

Table 2. Correlation between neuropsychological evaluation and neuroimaging exam (SPECT).

\begin{tabular}{lcccccc}
\hline \multirow{2}{*}{$\begin{array}{l}\text { Neuropsychological } \\
\text { evaluation }\end{array}$} & \multicolumn{2}{c}{ Neuroimaging Exam (SPECT) } & & Prevalence reason & Value \\
\cline { 2 - 5 } & $\mathrm{N}$ & $\%$ & $\mathrm{~N}$ & $\%$ & & \\
\hline of $\mathrm{p}$
\end{tabular}

Table 3. Comparison of the significance level in reading, writing and mathematics.

\begin{tabular}{lll}
\hline Reading & Writing & Mathematics \\
\hline Schooling & Schooling & Writing \\
$\begin{array}{l}\text { Neuropsychological } \\
\text { evaluation }\end{array}$ & $\begin{array}{l}\text { Neuropsychological } \\
\text { evaluation }\end{array}$ & Reading \\
Writing & Reading & Temporal lobes \\
Mathematics & Mathematics & \\
Temporal lobes & Temporal lobes & \\
\hline
\end{tabular}

with or without altered exams, there is a tendency of co rrelation between the exams made mainly in re la- tion to the area with higher hypoperfusion (left temporal and bilateral occipital lobe) with the function difficulties of reading, writing, mathematics and memo$r y$, according to the indices of $p$-value equal or lower than 0.05 (Fisher exact test), according to Chart 2.

When the reading and writing tests are specifically analyzed, it is possible to see that the values are equivalent in all the researched areas, including in the children who did not have alteration in the imaging exam, and therefore it is evidenced in the tests that the reading and writing processes are parallel, independently of the areas and functional routes involved, however the temporal and occipital lobes show a tendency to significance, due to the $\mathrm{N}=34$.

Considering the analysis of reading and writing, specifically, it is possible to see that both skills become 


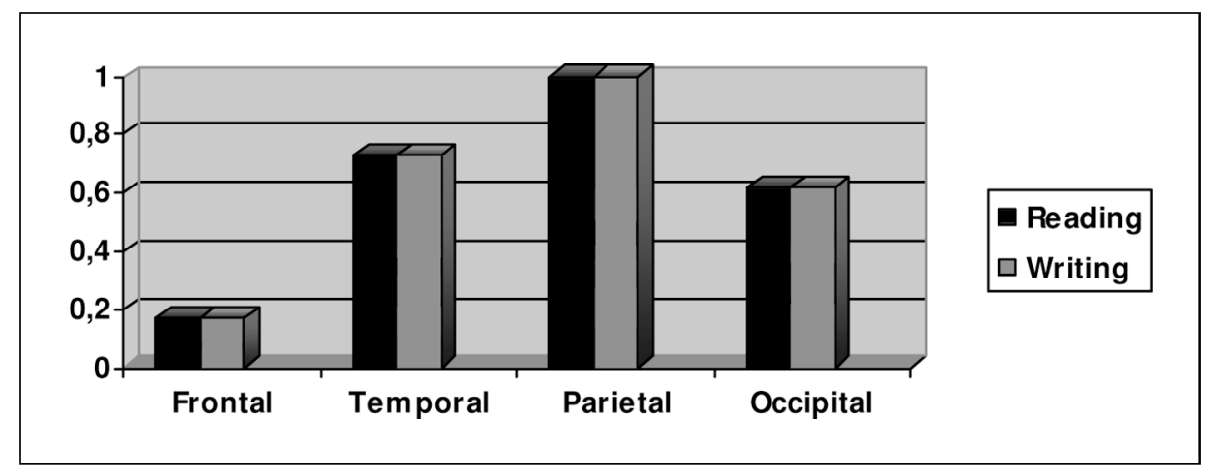

Charter 3. Correlation between reading and writing tests and cerebral areas.

or have a tendency to significance in common points, such as: schooling ( $p=0.07$ and 0.06 , respectively); neuropsychological evaluation ( $p=0.03$ for both); mathematics ( $p<0.01$ for both) and in the temporal hemispheres ( $p=0.07$ for both). Correlating reading and writing, $p<0.01$; and the opposite, writing and re a ding, maintains $p<0.01$. As for the mathematic skill, there is significance with: writing $(p<0.01)$, reading $(p<0.01)$ and temporal hemispheres $(p=0.01)$ according to Chart 3 and Table 3.

\section{DISCUSSION}

The specific learning disability exists when there is a significant discrepancy between normal intellectual ability and academic perf o rmance presented in one or more receptive or expressive skills, such as: reading, writing or mathematics ${ }^{19}$. Specifically speaking, the reading disability or dyslexia is the most common specific learning disability, being more associated to abnormalities or neurological dysfunctions.

The children diagnosed as dyslexic in this study demonstrated to have performances inferior to those expected to their age or maturational level, even though they presented normal intellectual potential and absence of other sensorial deficits.

As for the neuropsychological battery, the cognitive test showed levels compatible to nomality, where the IQs - verbal, execution and total - are equivalent qualitatively, not presenting significant differences among them; but their uses in the diagnostic p rocess are justifiable once they are indicators of the child's real performance. These data confirm Rotta's $\mathrm{s}^{20}$ findings that "the intellectual capacity is not the only responsible for success or failure at school", but that there are a number of factors associated with the lea ming process itself such as age, opportunities and functional adequacy. The neuropsychological batter- ies have been used as evaluation techniques of school performance and they have demonstrated a good number of results ${ }^{21}$. The factors measured by the association of tests such as language, memory, reading, writing and mathematics may determine the presence or absence of scholastic ability in a child.

In relation to the NLB, although it is a new instrument for science, different studies of different authors have demonstrated that through its subtests it is possible to discriminate the child with different levels of dyslexia, or even evaluate qualitatively the functional performance of these children. In the present study the subtests or exams that reflect these diffe rences are connected to the areas of reading, writing, mathematics and memory, exactly because they e $x$ ress more significance in academic aspects. Thus, we may consider several factors: besides the primary evidence of a neurological deficit as the precursor of dyslexia, we might propose, as in the classical work of Rapin and Allen ${ }^{22}$, that the low performance in some of the subtests connected to the academic area may be classified as: associated signals, which, according to the authors above cited, must be examined along with other signals, the concomitant ones, which imply the influence of biological factors, and become determinant in the occurrence of specific learning disabilities.

In the neurological exam, signs were detected which the literature considers as smaller or "soft signs" (characterized by a discrete disturb of the tonus, ext remity trembling, disdiadochokinesis, synkinesis, finger agnosia), which represent a subtle alteration of the nervous system and are manifested as abnorm a I movements, alterations in reflexes, associated movements, delay in motor acquisition, incoordination and general slowness ${ }^{23}$. However, the specificity and sensitivity of these signs is extremely relative, not 
indicating the exact presence of a neurological problem that may correspond to an academic difficulty ${ }^{12}$.

During the last decades the neuroimaging techniques have provided a significant impact for the investigation and correlation of the studies of the learning disabilities, revealing anatomical alterations ${ }^{1,6}$, besides dysfunctions in specific areas related to the neural architecture of reading and writing ${ }^{24,25}$. Researchers have demonstrated irregularities in the blood flow of the left hemisphere in dyslexic readers ${ }^{26}$. Flowers et al. ${ }^{26}$ found a reduction in the correlation between the volumes of blood flow of the left temporal lobe in participants with dyslexia, while controls demonstrated high correlation. In this study, as for the neuroimaging exams, the diagnostics demonstrated the involvement of specific areas, mainly a hypoperfusion in the mesial portion of the temporal lobe, left hemisphere, what might suggest an active participation of this region in the reading ability.

In favor of the correlation between the neuropsychological evaluation and the imaging exam, there is the fact that children with specific difficulties for reading and writing had reduction of the blood flow in regions of the cerebral cortex which are involved with highly determined functions such as:

Memory-whose capacity to acquire new information is a distinct cerebral function, located precisely in the mesial portion of the temporal lobe, which is responsible for other cognitive or perception capacities, for instance conscious rescue of memories and acquisition of flexible knowledge, relatable ${ }^{27}$. Thus, dysfunction of the temporal lobe causes dissociation between immediate memory and long term memory, determining diffe rences in the storage of new memories and learning.

Reading - d e t e rmined by the capacity of gathering information through written words, being, therefore, necessary a cerebral decodification which involves global, structural and contextual recognition (visual areas of the occipital cortex), and phonological synthesis and analysis (temporal-parietal association area, left angular gyrus $)^{28}$. It is known that, regardless of the language used, dyslexic people present deficits in the activation of the inferior and mesial regions of the left temporal lobe ${ }^{4,29-30}$, leading to the hypothesis that this hypoperfusion may be directly or indirectly secondary to cortical micro-lesions or neuronal ectopies. In this way, any alteration in blood flow in the region of the temporal lobe may bring serious deficits to the reading capacity of the individual.
Writing - writing involves a number of cerebral mechanisms and re $q u$ i res simultaneous and sequential integration of abilities such as memory, attention, motor skill, language and cognition. According to Luria ${ }^{31}$, writing as a function most importantly requires motor melody, which involves flexibility, liberation of movements simultaneously, stimulating some groups of muscles and at the same time inhibiting other muscular groups. Learning how to write implies, therefore, reproducing a word graphically, and it depends, basically, on the development of the phonological awareness of the child. Such awareness depends on the capacity of managing to decode and understand phonemes heard or read; therefore, in order to have a good performance in writing, it is necessary to have full development of the cerebral regions which develop reading and/or hearing.

Reading and writing abilities become significant in determined areas of this work when cerebral hemi$s p h$ e res and location are specifically correlated with the neuropsychological evaluation. The same happens with the schooling of the children in the rese arch. Such fact is justifiable once both abilities demand the same behavior and cognitive conditions for their execution; the correlation with mathematics is justifiable because in order to develop the capacity for such reasoning it is necessary to have well-developed reading and writing skills. In this way, for the learning of reading and writing it is necessary that all cerebral areas be functioning in an integrated and objective way so as to promote development; when one or more areas fail in this intricate process, specific reading, writing or general learning disabilities appear.

In conclusion, there is higher incidence of male child renthan female ones with complaints of specific reading disabilities. The alterations found in the neurdogical exam are not significant, although they express light signals compatible with learning disabilities. There is a discrepancy between the verbal IQ and the execution one in children with dyslexia. In the neuropsychological exam, the most evidenced deficits in children with dyslexia were: reading, writing, short term memory and mathematics. The imaging exams showed a hypoperfusion in areas involved in the reading and writing process. Both processes (reading and writing) are equivalent in terms of the functional areas involved and are similar in childre $n$ with alteration in the imaging exams and those without specific alterations. 


\section{REFERENCES}

1. Galaburda AM, Cestnick L. Dislexia del desarrollo. Rev Neurol 2003;36(Suppl):S3-S9.

2. Mccandliss BD, Noble KG. The development of reading impairment: a cognitive neuroscience model. Ment Retard Dev Disabil Res Rev 2003; 9:196-204.

3. Breier JL, Simos PG, Fletcher MG. Abnormal activation of temporopari etal language areas during phonetic analysis in children with dyslexia. Neuropsycologia 2003;17:610-621.

4. Paulesu E, Démonet JF, Fazio F, McCrory E, Chanoine V, Brunswick N. Dyslexia: cultural diversity and biological unity. Science 2001;291: 2165-2167.

5. Demonet JF, Taylor MJ, Chaix Y. Developmental dyslexia. Lancet. 2004; 17:247-248.

6. Galaburda AM, Sherman GF, Rosen GD, Aboitiz F, Geschwind N. Developmental dyslexia: four consecutive cases with cortical anomalies. Ann Neurol 1985;18:222-233.

7. Galaburda AM, Kemper TL. Cytoarchitectonic abnormalities in developmental dyslexia: a case study. Ann Neurol 1979;6:94-100.

8. Mesulam M. Imaging connectivity in the human cerebral cortex: the next frontier? Ann Neurol 2005;57:5-7.

9. Shaywitz SE, Shaywitz BA, Pugh KR, Fullbright RK, Constable RT, Mencl WE. Functional disruption in the organization of the brain for reading in dyslexia. Proc Natl Acad Sci USA 1998;95:2636-2641.

10. Cohen L, Dehaene S, Naccache L, Lehericy S, Dehaene-Lambertz G, Henaff MA. The visual word form area: spatial and temporal characterization of an initial stage of reading in normal subjects and posterior split-brain patients. Brain 2000;123:291-307.

11. Lou HC. Methylphenidate reversible hypoperfusion of striatal region in ADHD. In Conners K, Kinsbourne M (eds). Attention deficit disorder. Munchen: MMV Medizia Veriag, 1990.

12. Rumsey JM, Berman KF, Denckla MB, Hamburger SD. Regional cerebral blood flow in severe developmental dyslexia. A rch Neurol 1987; 44:1144-1150.

13. Ciasca SM. Correlação da avaliação neuropsicológica com exames complementares no diagnóstico dos distúrbios específicos de leitura e escrita: dislexia. Tese. Campinas, 2005.

14. Ortiz-Alonso T, Maestú F, Fernández-Lucas A, Amo C. Correlatos neuromagnéticos de la dislexia. Rev Neurol 2003;36(Suppl):S10-S12.
15. Wescheler D. Manual for the Wescheler intelligence scale for children. New York: Psychological Corporation, 1974.

16. Golden CY. The Nebraska neuropsychological children's battery. In Reynolds CR, Fletcher-Jansen E (eds). Handbook of clinical child neuropsychology. New York: Plenum Press, 1989.

17. Lefrève AB. Exame neurológico evolutivo. São Paulo: Sarvier, 1972.

18. Altman DG. Pratical statistics for medical research. London, 1991.

19. Hammil DD. A brief look at the learning disabilities movement in the United States. J Learn Disabil 1993;26:295-310.

20. Rotta N, Guardiola A. Distúrbio de aprendizagem. In Diament A, Cypel S (eds). Neurologia infantil. São Paulo: Atheneu, 1989.

21. Trei L. Difference in children brain activity offer clues to cause of dyslexia. Stanford Report, 2004.

22. Rapin I, Allen DA. Developmental language disorders logical consideration. In Kirk U (ed). Neuropsychology of language, reading and spelling. New York: Academic Press, 1983.

23. Gonçalves VMG. Neurologia dos distúrbios de aprendizagem. In Ciasca SM (ed). Distúrbios de aprendizagem: proposta de avaliação interdisciplinar. São Paulo: Casa do Psicólogo, 2003.

24. Larsen JP, Hoien T, Lundberg I, Odegaard H. Magnetic resonance imaging of the corpus callosum in developmental dyslexia. Cogn Neuropsycol 1992;9:123-134.

25. Duara R, Kushch A, Gross-Glenn K, Barker WW, Jallad B, Pascal S. $\mathrm{Ne}$ u roanatomic diffe rences between dyslexic and normal readers on magnetic resonance imaging scans. Arch Neurol 1991;48:410-416.

26. Bigler ED, O'neill RL, Howers NL. Technology in the assessment of learning disability. J Learn Disabil 1998;31:67-82.

27. Flowers DL, Wood FB, Naylor CE. Regional cerebral blood flow correlates of language processes in reading disability. Arch Neurol 1991; 48:637-643.

28. Rose M, Haider H, Weiller C, Buchel C. The role of medial temporal lobe structures in implicit learning: an event-related fMRI study. Neuron 2002;36:1221-1231.

29. Lozano A, Ramírez M, Ostrosky-Solís F. Neurobiologia de la dislexia del desarrollo: una revisión. Rev Neurol 2003;36:1077-1082.

30. Aylward EH, Richards TL, Berninger VW, Nagy WE, Field KM. Instructional treatment associated with changes in brain activation in children with dyslexia. Neurology 2003;61:212-219.

31. Luria AR. Higher cortical functions in man. New York: Basic Books, 1966. 